\title{
SURGICAL ASPECTS OF CEREBROVASCULAR DISEASE
}

\author{
W. F. C. Kennedy, B.M., B.Ch., Joe Pennybacker, M.D., F.R.C.S. \\ The Department of Neurological Surgery, The Radcliffe Infirmary, Oxford
}

VASCULAR lesions affecting the brain are important because of their frequency, their incidence in all age groups, their often profound and long-lasting clinical effects, and their social and economic repercussions on the community. Such lesions presented to a surgical department are usually highly selected, but for the purpose of this study one of us (W.F.C.K.) saw all, or practically all, cases of cerebrovascular disease admitted to the Radcliffe Infirmary for a period of 12 months in the years 1958-59. We found, among other things, ; that diagnosis can be very difficult, that it is sometimes impossible to say whether a patient has had a cerebral hæmorrhage or a thrombosis, and that special investigations will not always clarify the issue. The therapeutic problems confronting the surgeon include the decisions about whether and when to operate, and also the technical problems of operation. The increasing use of angiography in the last two decades has made an important contribution to the awareness of physicians and surgeons of the suitability of certain vascular lesions for surgical treatment, and what follows is an attempt to indicate the possibilities.

\section{Congenital Abnormalities \\ Aneurysms}

Cerebral aneurysms most commonly declare their presence by rupture, but may sometimes present without rupture on account of local pressure effects, or pain, or occasionally they are massive enough to behave as space-occupying lesions.

The particular susceptibility to aneurysm formation of the arteries composing the Circle of Willis, its branches and tributaries is due to localized congenital defects of the muscle coat (tunica media) which commonly occur in the angles of branching and which may be demonstrated histologically. Such defects alone may account for the development of aneurysms in young people, but other important factors are the degenerative changes in the muscle coat of atheromatous vessels and high blood pressure. When severe these latter factors may be entirely responsible for aneurysm forma- tion without an underlying congenital defect, and they particularly give rise to the fusiform type of aneurysmal dilatation. Mycotic aneurysms arising at the site of impaction of infective emboli are much rarer, but are an occasional cause of intra cranial hæmorrhage or suppuration.

The wall of a aneurysm consists only of a thit fibrous layer, reinforced to a variable ext mural thrombus, and it contains no muscle coat $\vec{\infty}$ Crawford (1959) found the site of rupture at the fundus of the sac in $84 \%$ of 105 post-mortem cases in which it could be identified by careful dissection Rupture at the neck was found in only three cases and rupture of the lateral wall accounted for the remainder. These findings, have an obvious bearing on the rationale of treatment by clippigign or ligation of the neck.

The pathology of aneurysmal hæmorrhage is limited to the aneurysm itself, for the state of the brain bears a more direct relation to the clinicas events and to the prospects of surgical treatment The actual hæmorrhage probably ceases within $\frac{1}{6}$ few seconds or minutes of rupture, but during this interval blood at arterial pressure escapes into the adjacent tissue plane, which is usually the sub-? arachnoid space, often the substance of the brain? and occasionally the subdural space. Thus, an intra-cerebral hæmatoma is a common complication, or the hæmorrhage may burst through tos the ventricular system, or a subdural hæmatoma may occasionally be formed, although it is rarely ao large one. Massive subarachnoid bleeding may lead to the filling of the basal cisterns with solide clot, and this is usually present at autopsies on fatal cases, when often the ventricles are full of? clot as well. Less severe hæmorrhage may alson interfere with the patency of the intra-cerebrap and extra-cerebral pathways of the cerebro $N$ spinal fluid and may thus cause internal or externalew hydrocephalus, which contributes to the increaseo in intracranial pressure in the acute phase. Latero the pathways affected in this manner may be obliterated by fibrosis and surgical relief with a by-pass operation may be necessary after recoveryo from the initial effects of the hæmorrhage has?

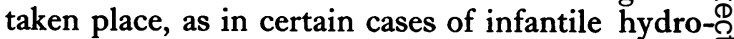


cephalus following birth trauma (Kibler, Couch and Crompton, 196r).

Subdural hæmatoma is a rare complication of aneurysmal rupture and can only be diagnosed with certainty by angiography; its presence constitutes an indication for operation in its own right, whatever the nature and site of the underlying vascular anomaly. It can be associated with severe and rapidly fatal hæmorrhage, but sometimes it is not discovered until some days or weeks after the onset (Clarke and Walton, 1953).

Narrowing, or spasm, of the cerebral vessels is a common angiographic or operative finding in the acute stage of subarachnoid hæmorrhage (Potter, 1959) and one peculiar to this condition. It is not necessarily confined to the vessel bearing the aneurysm which has ruptured, but is usually greatest in this vessel and therefore it can be a valuable guide to the site of rupture in a case where multiple aneurysms are present. It usually lasts from one to three weeks and may be severe enough to cause local or widespread infarction. Certainly it renders the brain exceptionally liable to œdema or infarction and vulnerable to injury by even the gentlest surgical manipulation. Ischæmic damage may also result from mechanical stretching, disruption and thrombosis of vessels, some of the most sensitive being the small perforating branches of the Circle of Willis, which ascend to the vital deep cerebral structures.

Occasionally an intracavernous carotid aneurysm ruptures to form a carotid-cavernous fistula. Other aneurysms in this situation may enlarge to fill the sinus without rupturing, acquiring thereby an extra coat of dura, and further enlargement may then take place, sometimes to fill the middle cranial fossa. These aneurysms often cause pain, especially round the eye, and local pressure effects which include vascular congestion of the orbital contents, proptosis, and lesions of the second, third, fourth and fifth cranial nerves, and of the ocular sympathetic fibres. They may, therefore, simulate an intrasellar or parasellar tumour. X-rays may show local bone erosion in the optic foramen, superior orbital fissure, sella turcica, and floor of the middle cranial fossa, and the aneurysm may calcify. Long-term survival with no more than ocular manifestations is common, but surgical treatment may be required on account of pain, progressive visual failure or proptosis (Meadows, I96I).

The definitive treatment of ruptured aneurysm has to be considered in relation to what is known of the natural course of the disease and each individual case presents its own particular problems because so many variable factors influence the possibility and effectiveness of surgical treatment. Salient amongst these are the site, size and shape of the aneurysm, the presence of multiple aneurysms, the severity and site of hæmorrhage,' the time since it occurred, and the clinical state of the patient. Thus, there are rapidly fatal cases in which, at autopsy, the cerebral damage is so extensive that it is obvious that no treatment could have been worth while. Other factors which have to be taken into account are the number of previous hæmorrhages, the adequacy of the collateral circulation as demonstrated by careful angiography, and the age and general health of the patient, with special reference to the cardiovascular system.

The results of treatment are also particularly difficult to assess against the background of such a variable illness and the differing objectives of surgical treatment must also be kept in mind. These are to exclude the aneurysm from the circulation in order to prevent recurrent hæmorrhage and to evacuate an intracranial hæmatoma when such is present. Less commonly, operation is performed for pain or ocular manifestations of unruptured aneurysms. To complicate the situation further is the variety of different operations undertaken: the theoretical procedure of choice is obliteration of the aneurysm by clipping or ligating its neck without jeopardizing the arteries in relation to it. This is not always practicable without sacrifice of the circulation distal to the aneurysm, and it may be impossible to predict the effect of intervention. Other possibilities include packing and wrapping the aneurysm with muscle, or acrylic resin (Dutton, I959), ligation or clipping of the feeding vessel proximal to the aneurysm, or both proximal and distal to it (' trapping '), or ligation of the common or internal carotid arteries in the neck.

It is the general experience that the risks of all operations for ruptured aneurysms are greatest in the first few days after hæmorrhage; at this stage the technical problems of the intracranial approach are the most difficult, and the incidence of hemiplegia after carotid ligation in the neck is the highest. Also, the adequate demonstration of the cerebral vascular tree by angiography is often limited by the presence of spasm. Yet if the mortality and morbidity from early recurrent hæmorrhage are to be reduced, investigation and treatment must be instituted in the early days after rupture, for the peak incidence of this complication is in the second and third weeks (Walton, 1956).

At present it is by no means certain that operation in the acute stage of bleeding reduces mortality and morbidity significantly. Many of the good results claimed for surgery are now thought to be attributable mainly to selection of more promising cases and to failure to assess the results against a truly comparable control series. Thus McKissock, Paine and Walsh (196ob), in a retrospective analysis of 599 cases of ruptured aneurysm in which the lesion could be angiographically 
demonstrated, found that their overall mortality for the surgically treated cases was $33 \%(47 \%$ in the conservatively treated group). The mortality of operations performed within three days of the hæmorrhage was nearly $50 \%$. The mortality in conservatively treated patients who had already survived a corresponding interval of time was nearly $75 \%$, but this figure was weighted by the unusually high mortality $(92 \%)$ in those admitted within 24 hours of the hæmorrhage. For those who survived from two to three weeks before operation the mortality was still as high as $30 \%$, whilst amongst the non-surgical group of survivors after this interval the mortality was $20 \%$. For all those who survived four or more days after the hæmorrhage the natural mortality was $30 \%$ and the operative mortality $26 \%$. Furthermore, there was a much higher proportion of totally and partially disabled survivors in the surgical group than in the conservative group, whereas the proportion of those who could return to full work was roughly the same in each. The operative mortality when the patient was still in coma at the time of operation was $80 \%$, whereas it was $20 \%$ in alert patients, and the results of conservative treatment in corresponding groups of patients were only a little worse. The authors emphasize that, owing to the factors of selection and difficulty of control, no final conclusions can yet be drawn, and they are making a prospective clinical trial to establish the facts more clearly.

On the other hand, if investigation and operation are delayed until three or four weeks after rupture, the risks are much lower, but so also are the risks of recurrent hæmorrhage. After an interval of a few months from a single hæmorrhage it is questionable whether the risks of operation are less than the risks of doing nothing. Furthermore, one is now concerned only with those who survived the acute illness and who naturally carry a more favourable prognosis.

In this department the policy is to delay angiography until the patient has made a satisfactory clinical recovery from the immediate effects of the hæmorrhage with respect to his state of alertness, or until failure to improve gives rise to the suspicion of an intracranial hæmatoma. When a hæmatoma is present operation for its removal is undertaken and, when possible, the causative vascular anomaly is dealt with. If the clinical disability is severe in the absence of an intracranial hæmatoma, operation is delayed until it is evident that a useful degree of recovery is going to take place.

Operations on intracranial aneurysms carry somewhat exceptional risks. The aneurysm may rupture during exposure and the control of the hæmorrhage may necessitate the occlusion of a more important vessel than had been contemo plated. This may lead to a serious and permanen disability where none existed before. Sometime\$ in apparently straightforward procedures, subsequent thrombosis of adjacent vessels may also: cause profound disability. Sometimes a clip whick seemed securely applied works off the aneurysin and hence it is important to check the result b post-operative angiography. Not infrequently tho precise shape and size of the aneurysm as seen on the angisgram bears little relation to reality as disclosed at operation, so that it may not be possible to carry out the planned procedure. Angiography, after all, only visualizes the interio of the aneurysm.

To some extent these risks and the technical difficulties of exposure can be reduced by ancillar. aids, such as hypothermia (which reduces braifp volume and allows temporary obliteration of the cerebral circulation without infarction) (McKis= sock, Paine and Walsh, I96Ja), hypotensive anæsthesia (which reduces the risk of rupturo during exposure and facilitates its control should it occur), and intravenous urea (which reduces) the amount of retraction necessary by decreasing brain volume) (Stubbs and Pennybacker, 1960) Even so, the state of the brain after a recont hæmorrhage is unfavourable for precise and poos longed dissection, and at least some of its increased vulnerability remains. These operations are therefore sometimes followed by an increase is the existing neurological deficit, or the appearance of such where none existed before. This complica tion may be accompanied by obstruction of $\mathbb{Q}$ cerebral vessel demonstrable by angiography, bu $\overrightarrow{\widehat{E}}$ often it is not. Thus, the treatment may bring about the very disability it was undertaken to prevent.

Operations are undertaken for unrupture aneurysms when there is pain, progressive oculary palsy or proptosis. The lesion is usually on the distal segment of the internal carotid artery and ligation of the common carotid artery in the necto is a satisfactory form of treatment. Sometimes as similar operation is undertaken for similar reasons or for a troublesome bruit, in carotid-cavernous fistula, although there is a chance of spontaneous cure (Potter, 1954) or long survival without dise abling symptoms in this condition.

In recent years there have been reports of aneurysms (and angiomatous malformations) is the posterior fossa successfully treated according to the principles employed for those situated in the supra-tentorial compartment. Undoubtedly these lesions are no longer to be regarded as uniformlyo inoperable (Logue and Monckton, 1954; Dimsdalê. and Logue, 1959). 


\section{Angiomatous Malformations}

The essential component of these lesions is an arterio-venous anastomosis, which is not neoplastic, but which may progressively enlarge, with increasing dilatation of its feeding and draining vessels, on account of the local hæmodynamic conditions and by the excavation of small blood cysts following hæmorrhage (Potter, 1955). Unlike the comparable arterio-venous malformations of the limbs, it is unusual to find an associated secondary circulatory disturbance (cardiomegaly, tachycardia, plethora).

These malformations may be small or large, may occur anywhere in the brain, and are sometimes associated with aneurysms. They commonly give rise to epilepsy with focal features, by rupture to subarachnoid or intra-cerebral hæmorrhage (about $5 \%$ of such hæmorrhages result from angiomatous malformations) or occasionally to progressive neurological disability by causing ischæmia of the adjacent brain tissue, or by gradual enlargement. They may cause headache simulating migraine. Occasionally they obstruct the cerebrospinal fluid pathways and cause obstructive hydrocephalus; they may calcify and can then be suspected from the radiological appearance. Except in the rare cases which have a bruit or an associated external vascular anomaly of the scalp or face (Sturge-Weber syndrome), we rely on angiography for final diagnosis. The crucial feature is venous filling in the arterial phase, which also provides further evidence of their essential nature. This, together with the characteristic tangle of tortuous and dilated arteries and veins, distinguishes them from the abnormal vascular patterns of certain tumours.

The satisfactory delineation of an angioma may demand bilateral carotid and vertebral angiography if its total extent, arterial supply and venous drainage are to be demonstrated. Moreover, as the speed of circulation through them may vary enormously, serial angiography is almost essential. Some of these lesions are so extensive and in such eloquent parts of the brain that they cannot be removed. But some are accessible and if one or more hæmorrhages have occurred, or if epilepsy proves refractory to medical treatment and constitutes a disability, the lesion should be extirpated (Paterson and McKissock, 1956). It should be said that, in our experience, hæmorrhage from angiomatous malformations is much less lethal than from aneurysms. It should also be said that we have no satisfactory long-term assessment of the results of these operations undertaken for the relief of epilepsy. Excision of an angioma leaves a scar which may be as potently epileptogenic as was the angioma.

\section{Sturge-Weber Syndrome}

This consists of a diffuse angiomatous malformation of the pia-arachnoid and cortex of one cerebral hemisphere associated with a similar cutaneous lesion (port-wine stain) in some or all of the ipsilateral trigeminal distribution, and occasionally also in other parts of the body. It is not often a surgical problem and hæmorrhage is unusual, but fits, mental retardation, abnormalities of behaviour, hemiplegia and sometimes athetosis may present a problem of social management which may be partly solved by hemispherectomy (Falconer, I960).

\section{Subarachnoid Hamorrhage with Normal Angiograms}

A considerable proportion of a series of cases of subarachnoid hæmorrhage will have normal carotid angiograms. Walton (1956) quotes various authors who found $10 \%$ to $20 \%$ of such cases in their series of patients with subarachnoid hæmorrhage. This proportion will be reduced if vertebral angiography is carried out. This investigation will sometimes display aneurysms or angiomas in the posterior fossa, or in the posterior part of the supratentorial compartment when the posterior cerebral arteries have failed to fill on carotid angiography. Thus, Spatz and Bull (1957) displayed such lesions in $26 \%$ of 60 cases of subarachnoid hæmorrhage with negative carotid angiograms (the ages ranging from 6 to 66 years), even when the posterior cerebral arteries were filled by the carotid injections in a third of these cases. Half of the lesions were aneurysms, half were angiomatous malformations.

The greater difficulty of vertebral angiography militates against its routine use in the investigation of subarachnoid hæmorrhage, and it may even be necessary to inject both sides to display or exclude with certainty an aneurysm at the origin of the ipsilateral posterior inferior cerebellar artery (Dimsdale and Logue, 1959). When bilateral carotid angiograms have proved negative vertebral angiography is usually employed in the younger, healthy patients. If this is also negative, a favourable prognosis can be given, as the lesion has presumably destroyed itself, or undergone a natural cure by thrombosis. But occasionally there will be a recurrence and in these cases the lesion is probably too small to be visualized by angiography. We also employ vertebral angiography when there are clinical symptoms or signs to suggest a lesion on the vertebral system.

\section{Other Causes of Subarachnoid and Intra-cerebral Hamorrhage}

Although most cases will have demonstrable aneurysms or angiomatous malformations, and 
some will have no demonstrable vascular anomaly, a small proportion will have other forms of intracranial pathology (when we exclude those due to constitutional diseases, such as hypertension and blood diseases). Thus, a spontaneous subarachnoid hæmorrhage may cause the first symptoms and constitute the presenting clinical picture of chronic subdural hæmatoma or intracranial tumour; sometimes a traumatic subarachnoid hæmorrhage may masquerade as a spontaneous one if a detailed history is not available. We have seen cases of meningioma, glioblastoma multiforme, oligodendroglioma, acoustic nerve tumour, subdural hæmatoma, sagittal sinus thrombosis and traumatic extradural hæmatoma present in this way, with sudden headache, perhaps with depression of consciousness, with fresh blood in the cerebrospinal fluid and without previous symptoms. In these cases angiography will usually indicate the nature of the lesion.

Spontaneous Intra-cerebral Hamorrhage in Young People without Visible Anomalies

There is a group of cases of intra-cerebral hæmorrhage in otherwise perfectly healthy young people, usually in the second, third or fourth decade, in whom angiography, although showing the hæmatoma, fails to display an underlying vascular anomaly (aneurysm or angioma); neither is one seen at operation. Such hæmorrhages are generally held to have originated in small angiomatous malformations which have been destroyed by the hæmorrhage. Sometimes the remnants can be found by careful dissection at autopsy (Russell, 1954). The prognosis is favourable in those who survive if no irreversible neurological damage has been sustained, and if the hæmatoma is evacuated, when a remarkable degree of neurological recovery may occur. The hæmorrhage is often more superficially placed in the cerebral hemisphere, in the subcortical layer, than the deeply placed hæmorrhage of arteriosclerosis and hypertension. It often appears much larger at operation than would have been anticipated from the angiograms.

\section{Acquired Disease Apoplexy}

Cerebral hæmorrhage occurring in the older age-groups is due to atheroma and hypertension (occasionally to aneurysm) and the prognosis is influenced adversely thereby. The hæmorrhage is often small and deeply placed in the cerebral hemisphere, with correspondingly more severe neurological damage by smaller lesions. These do not often benefit from attempts at surgical evacuation, which can only add to the neurological damage in the process. Sometimes, however, the hæmorrhage is large enough and superficial enough to allow surgical access, but the general experienge is that little is to be gained by attempting sues operations within the first fortnight or so. If, aft that time, significant clinical recovery has not yet begun, aspiration of the liquefied hæmatoma witl sometimes be followed by partial recovery. $F_{0}^{D}$ this purpose a simple burr-hole made under local anæsthesia is adequate, and such a limited pro cedure has obvious advantages when dealing wigh this group of cases.

The prognosis is influenced by the patholog\%: the underlying vascular disease is usually diffuste and there are corresponding risks of further episodes of cerebral hæmorrhage, or of ischæmac disease in the brain or other organs.

Occasionally we have encountered cases of cer? bellar hæmorrhage due to degenerative arterial disease; these are not common, but sometimes the hæmatoma requires evacuation, which usuaity entails a full cerebellar exploration rather than: simple burr-hole and aspiration.

\section{Cerebral Thrombosis}

Cerebral thrombosis and thrombo-phlebitis afe not amenable to surgical treatment and conce the surgeon only as a diagnostic problem or as complication of any operation in the elderly $y_{\infty}$ or sometimes after operations for aneurysms younger people.

Any of the intracranial vessels may be affe and commonly it is one too small to visualize angiography and in these cases the thromboses are often multiple. Thrombosis of the larger intracranial vessels, and especially of the middfie cerebral artery, may occur spontaneously in the young and usually it is not possible to make clinical distinction between this lesion and carotie thrombosis. Thrombosis of the posterior cerebra arteries may be spontaneous, or secondary to tentorial pressure cone, and in the latter case may give rise to hemianopia as a false localizin sign in cases of intracranial tumour.

Ischæmic damage to the brain does not neceß sarily lead to infarction, for there may be fut recovery after a temporary and severe disruption of cerebral function lasting sometimes as long as week or a fortnight before any improvement $\underline{\underline{1 S}}$ evident. The recovery is presumably accounted for by the elaborate anastomoses between the intra cranial vessels and by recanalization.

There is still no certain way of distinguishiri between cerebral hæmorrhage, thrombosis an embolism. The latter is usually diagnosed onfy when there is a clinically recognizable source of emboli; hæmorrhage and thrombosis are each compatible with a sudden or progressive onset $\mathbb{P}$ symptoms, with retention or depression of cop sciousness, with presence or absence of headache, 
with slight or severe neurological deficit, with presence or absence of subarachnoid blood and with presence or absence of a space-occupying lesion on the angiograms.

Occasionally such lesions have an atypical clinical development which may be gradually progressive over several days and associated with fever, meningeal irritation and a pleocytosis in the cerebrospinal fluid (perhaps as many as a thousand cells, though usually a few hundred). In these cases an initial clinical diagnosis of meningitis or abscess may be made.

The slow progression over months of small ischæmic lesions in the brain may cause confusion with tumour, and this may be impossible to resolve except by the demonstration of cerebral atrophy by air-encephalography or ventriculography. Commonly such cases present with progressive mental deterioration and evidence of diffuse pyramidal affection, but sometimes the signs are remarkably focal, even with focal epilepsy of late onset.

\section{Carotid Artery Disease}

The recent advances in the surgery of arterial reconstruction have led to renewed interest in thrombosis and stenosis of the carotid and vertebral arteries in their extracranial course (Rob, 1959). The arterial lesion may range from a total obliteration by thrombosis, or congenital atresia, to a slight degree of stenosis by atheromatous plaques. These plaques have a particular affinity for the origins of the main vessels and for their points of bifurcation, in particular the origin of the internal carotid artery.

The associated cerebral lesion may be a massive infarction sufficient to cause death, or total and permanent loss of function of the appropriate cerebral hemisphere, or it may be much less than this, and partly or wholly recoverable spontaneously, or there may be no detectable abnormality. There may be intermittent and transient attacks of cerebral disturbance, such as hemiparesis, perhaps associated with monocular blindness. These intermittent symptoms are especially likely to occur at times of general circulatory stress (e.g. hypotensive phases or anæmia) or when the collateral and compensatory blood supply is threatened by mechanical means, such as certain movements of the neck and shoulder girdle, or by diffuse arterial disease. Thus, a complete carotid occlusion may cause no symptoms at all until such time as the other carotid and the vertebral arterial systems become narrowed sufficiently to cause symptoms of cerebral ischæmia. These may, therefore, be precipitated by the failure of the collateral circulation rather than by the original arterial obstruction. The important consideration is the state of all the extra-cranial cerebral arteries rather than that of any one of them alone (Hutchinson and Yates, I956, I957; Schwartz and Mitchell, r96I).

This conclusion agrees with the common surgical experience of the rarity of deficiency. symptoms after ligation of the common carotid artery in the neck for aneurysm, provided this is done after the acute effects of the hæmorrhage have subsided. Although ischæmic manifestations, such as hemiplegia or aphasia, may appear at the time of operation or within a few days thereafter, late complications of this type are very rare. Also, cases of long-standing bilateral carotid occlusion are known in which there have been no features of cerebral ischæmia at all; in these cases the whole cerebral blood supply must have passed up the vertebral and basilar arteries. There is, however, no information about what happens when people who have had successful carotid ligations for aneurysm before middle age enter the common age-group of cerebral arteriosclerosis. It would be instructive to know whether they are more or less prone to ischæmic lesions than a control group.

The abundance of the normal cerebral collateral circulation renders the assessment of results of reconstruction operations on the carotid arteries in the neck particularly difficult. $A$ priori, it would seem illogical to undertake these operations in the presence of established cerebral infarction, as witnessed by severe or complete loss of function in a hemisphere, and, indeed, the restoration of arterial flow through an area of infarction may well precipitate a fatal issue owing to hæmorrhage. When the neurological deficit has been temporary and is already recovering spontaneously, this fact is evidence of the present adequacy of the collateral circulation. An operation on the carotid could then only help the patient by preventing a recurrence of symptoms in the future and would have to be undertaken without jeopardizing the existing circulation. The tortuous course and relations of the carotid artery, and the sensitivity of its area of supply to anoxia, add technical difficulties and problems which are absent from the surgery of other peripheral vessels. At present it seems that patients most likely to benefit from this kind of surgery are those with localized stenosis in one artery, causing frequent, intermittent symptoms.

\section{Conclusion}

It is hardly surprising that problems abound in the diseases of so complex an arrangement as the cerebral vascular system, on which the working of the brain depends. It is also clear that understanding of these varied disorders is still incom- 
plete and much more will have to be learned about them before ideas of management cease to change as restlessly as in recent years.
We are particularly grateful for the friendly co-opera tion of the physicians of the Radcliffe Infirmary and for their generosity in allowing us to see so many of the patients.

\section{REFERENCES}

Clarke, E., and Walton, J. N. (1953): Subdural Hæmatoma Complicating Intracranial Aneurysm and Angiome Brain, 76, 378.

CRAWFORD, T. (1959): Some Observations on the Pathogenesis and Natural History of Intracranial Aneurysms, Neurol. Neurosurg. Psychiat., 22, 259.

Dimsdale, H., and LoGUe, V. (I959): Ruptured Posterior Fossa Aneurysms and their Surgical Treatment, Ibid., 22, 20 8

Dutron, J. (1959): Acrylic Investment of Intracranial Aneurysms, Brit. med. F., ii, 597.

FALCONER, M. A. (1960): The Treatment of Encephalotrigeminal Angiomatosis (Sturge-Weber Disease) by Hemî spherectomy, Proceedings of the Society of British Neurological Surgeons in F. Neurol. Neurosurg. Psychiat., 23, 85

Hutchinson, E. C., and Yates, P. O. (1956): The Cervical Portion of the Vertebral Artery: A Clinico-Pathological Study, Brain, 79, 319.

(I957): Carotico-Vertebral Stenosis, Lancet, i, 2.

KibleR, R. F., Couch, R. S. C., and CROMPton, M. R. (I96I): Hydrocephalus in the Adult following Spontaneous Subarachnoid Hæmorrhage, Brain, 84, 45 .

Logue, V., and Monckton, G. (1954): Posterior Fossa Angiomas. A Clinical Presentation of Nine Cases, Ibid., 77, 25 s.

McKissock, W., Paine, K. W. E., and WaLSH, L. S. (1960a): The Value of Hypothermia in the Surgical Treatment 80 Ruptured Intracranial Aneurysms, Y. Neurosurg., 17, 700.

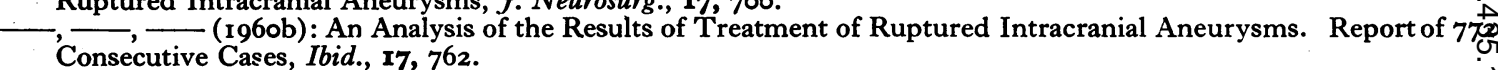

Meadows, S. P. (196r): Intracranial Aneurysms, ' Medical Annual ', p. 325.

Paterson, J. H., and McKissock, W. (I956): A Clinical Survey of Intracranial Angiomas with Special Reference to their Mode of Progression and Surgical Treatment: A Report of 1 10 Cases, Brain, 79, 233.

Potrer, J. M. (1954): Carotid-Cavernous Fistula. Five Cases with 'Spontaneous' Recovery, Brit. med. F., ii, 786. $\vec{C}$

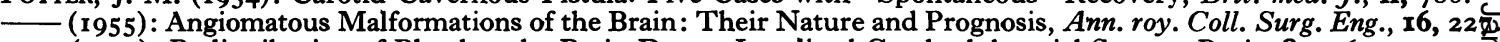

(1959): Redistribution of Blood to the Brain Due to Localized Cerebral Arterial Spasm, Brain, 82, 367.

RoB, C. (1959): The Surgical Treatment of Stenosis and Thrombosis of the Internal Carotid, Vertebral and Common Carotid Arteries, in Symposium on Cerebrovascular Disease, Proc. roy. Soc. Med., 52, 549.

Russell, D. (1954): Discussion: The Pathology of Spontaneous Intracranial Hæmorrhage, Ibid., 47, 689.

Schwartz, C. J., and Mitchell, J. R. A. (I96I): Atheroma of the Carotid and Vertebral Arterial Systems, Brit. me ii, 1057 .

Spatz, E. L., and Bull, J. W. D. (1957): Vertebral Arteriography in the Study of Subarachnoid Hæmorrhage Neurosurg., 14, 543.

StubBs, J., and PenNYBACker, J. (1960): Reduction of Intracranial Pressure with Hypertonic Urea, Lancet, i, 1094.

WaLton, J. N. (1956): ' Subarachnoid Hæmorrhage'. Edinburgh: Livingstone. 